\title{
Synergies between assisted reproduction technologies and functional genomics
}

\author{
Pasqualino Loi ${ }^{1 *+}$, Paola Toschi ${ }^{1 \dagger}$, Federica Zacchini ${ }^{1,2}$, Grazyna Ptak ${ }^{1,2,7}$, Pier A. Scapolo ${ }^{1}$, Emanuele Capra ${ }^{5}$, \\ Alessandra Stella ${ }^{5}$, Paolo Ajmone Marsan ${ }^{3,4}$ and John L. Williams ${ }^{6}$
}

\begin{abstract}
This review, is a synopsis of advanced reproductive technologies in farm animals, including the discussion of their limiting factors as revealed by the study of offspring derived from embryos produced in vitro and through cloning. These studies show that the problems of epigenetic mis-programming, which were reported in the initial stages of assisted reproduction, still persist. The importance of whole-genome analyses, including the methylome and transcriptome, in improving embryo biotechnologies in farm animals, are discussed. Genome editing approaches for the improvement of economically-relevant traits in farm animals are also described. Efficient farm animal embryo biotechnologies, including cloning and the most recent technologies such as genome editing, will effectively complement the latest strategies to accelerate genetic improvement of farm animals.
\end{abstract}

\section{Background}

\section{Brief history of reproduction biotechnologies}

Artificial insemination (AI) was first performed in dogs by Spallanzani in 1784, but this procedure only became routine in the mid 1900s when it was applied to a wide range of species. AI has had the greatest impact in dairy cattle breeding. While AI is an effective way to disseminate the genetics of sires, the portfolio of embryo biotechnologies now available has expanded the opportunities to increase selection pressure on the female side. In the 1980s and 1990s, major advances were made in multiple ovulation and embryo transfer (MOET), ovum pick up (OPU) [1-3] and in vitro embryo production and freezing [4-7] (Fig. 1). In addition, embryo multiplication procedures, including embryo splitting [8-10] and cloning by nuclear transfer of embryonic cells, have been developed [11-14]. The long sought after goal of multiplying unique genotypes culminated with the production of the first mammal cloned by nuclear transfer from

\footnotetext{
*Correspondence: ploi@unite.it

${ }^{\dagger}$ Pasqualino Loi and Paola Toschi: first co-authorship

' Laboratory of Embryology, Faculty of Veterinary Medicine, University

of Teramo, Teramo, Italy

Full list of author information is available at the end of the article
}

a somatic cell [15-17] (Fig. 2). This triggered a negative reaction from those who feared potential applications of this technology.

Paradoxically, although reproduction specialists and quantitative geneticists share the common goal of achieving genetic improvement, these two groups of scientists do not collaborate on a regular basis. With the exception of MOET, embryo biotechnologies have not been used extensively in breeding programs. Fuelled by advances in DNA sequencing and genotyping techniques and by falling costs, genomic selection, first mooted in 2001 [18], is now possible. This approach provides the opportunity to genetically select embryos and increase the use of in vitro methods to accelerate genetic improvement (see companion reviews of the ISAFG meeting in this issue).

In vitro embryo production is not yet reliable, and still essentially uses protocols that were developed in the 1990s. However, we are beginning to understand the molecular mechanisms that are at play during development, and the factors that need to be improved. The techniques used for in vitro production and culture of embryos can lead to alterations in epigenetic programming, e.g. modifications of the DNA methylation patterns. These changes have an effect on the expression of 

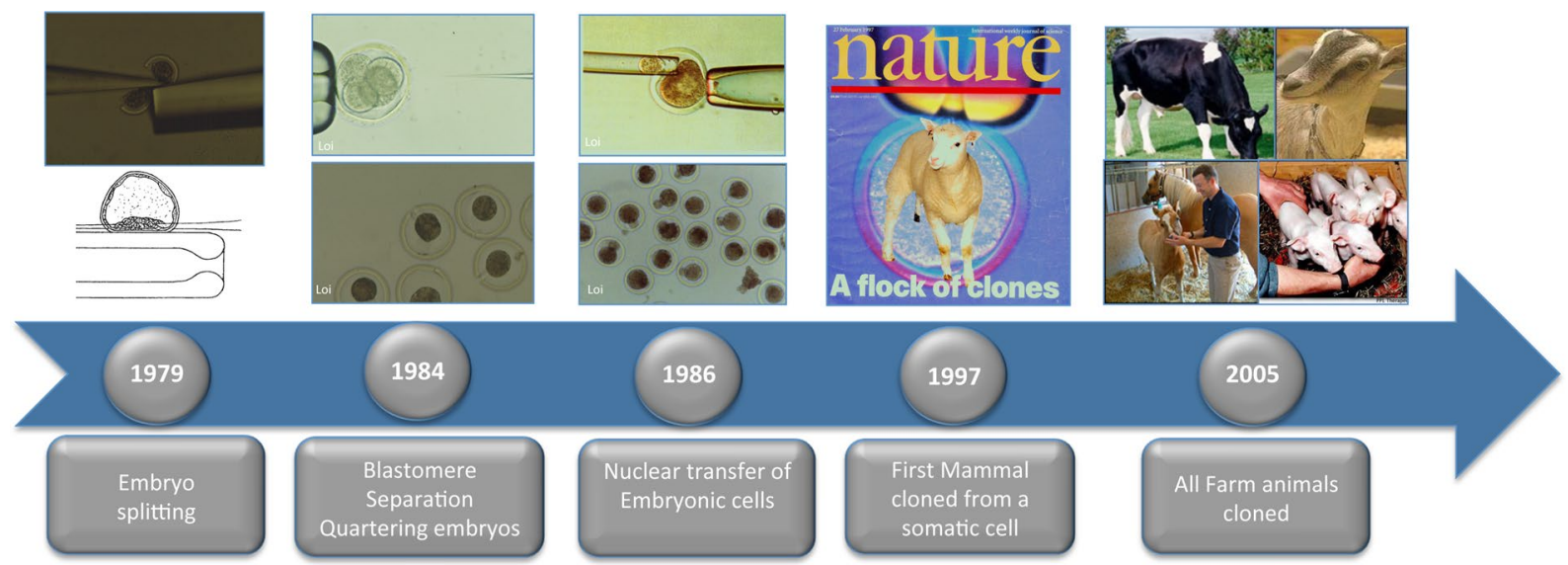

Fig. 1 Timeline of the development of reproductive biotechnologies in farm animals

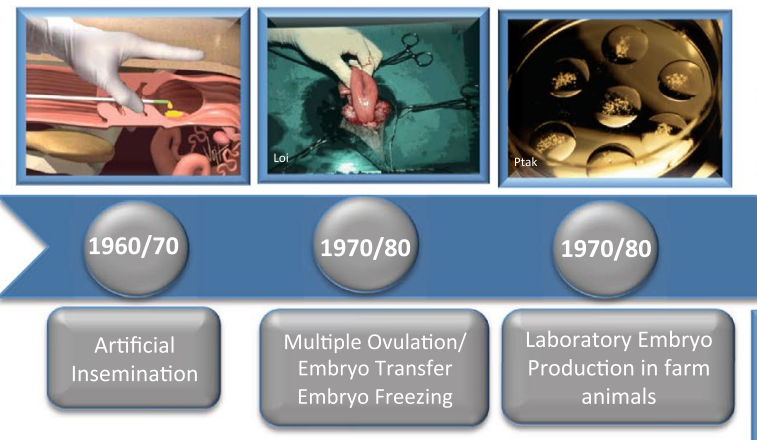

Fig. 2 Timeline of embryo multiplication technologies in farm animals

imprinted genes and hence on developmental abnormalities, resulting in foetal overgrowth [19] and failure [20, 21]. Early studies on cloning showed that synchronisation of the nucleus from donor cells with that of the recipient is necessary to sustain the development of a viable embryo [15], most probably through epigenetic reprogramming. However, current cloning techniques are not significantly better than those of the initial cloning reports [22, 23] (Fig. 3), and the success rate of producing viable offspring is still less than $1 \%$. With this low success rate, cloning cannot be used in programs for the genetic improvement of farm animals, but is an approach that can be used for research. Cloning may also be used to create "back-up" individuals of animals with unique genetic features [24].

Advances are, however, being made in the field of oocyte recovery, culture and in vitro fertilisation. For example, young lambs of 3 to 4 weeks of age have a large number of follicles and, after stimulation, up to 100 follicles can be routinely produced, which yield 60 to 70 oocytes by OPU. More than $50 \%$ of these oocytes are competent and will develop into blastocysts following in vitro fertilisation [25]. This process of juvenile in vitro fertilisation and embryo transfer (JIVET) allows large numbers of full-sibs to be obtained from lambs at a few weeks of age, thus greatly reducing the generation period. Improvements in this approach could accelerate genetic progress by producing large numbers of lambs from elite ewes. JIVET can also be used to produce large numbers of embryos for genetic manipulation, as discussed below.

\section{New technologies: from SNPs to whole-genome sequencing}

The last 10 to 15 years have witnessed rapid advances in approaches for the analyses of DNA sequence and structure. Genome sequence data from next-generation sequencing platforms have identified large numbers of single nucleotide polymorphisms (SNPs), high throughput genotyping platforms have made SNPs the most widespread and efficiently genotyped genetic markers. 


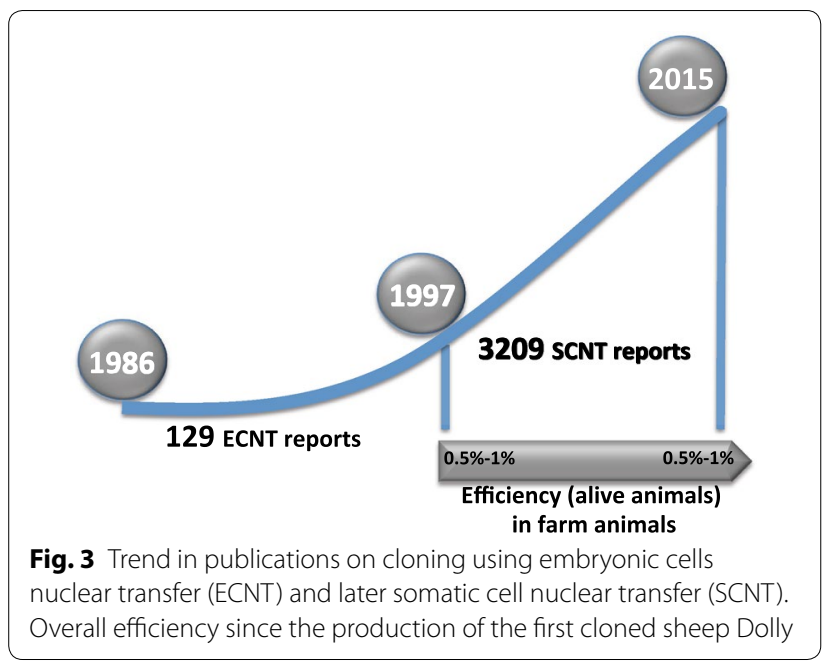

High-density SNP data can be used in genomic selection (GS) [26] and in genome-wide association studies (GWAS) to identify quantitative trait loci (QTL) for production related traits, such as meat and milk composition, fertility or disease response (see $[27,28])$. These data can be used for both in vivo and in vitro breeding applications. SNP data can also be analysed to detect chromosomal regions with loss of heterozygosity (LOH). LOH haplotypes have a significantly reduced frequency, or are absent in the homozygous state. Such haplotypes are likely to contain recessive, deleterious or lethal genetic variants [29-33]. The combined use of SNPs, exome and whole-genome sequencing data from more than 25,000 Fleckvieh cattle led to the detection of four $\mathrm{LOH}$ regions [34]. Combining LOH information with large wholegenome sequence datasets, such as the 1000 bull genome project (http://www.1000bullgenomes.com) has identified candidate lethal mutations in genes such as $S M C 2$ (structural maintenance of chromosomes) and COL2A1 (collagen, type II, alpha 1) [34, 35]. Interestingly, some of these deleterious variants are segregating at a significant frequency in the populations and contribute to negative genetic trends in fertility traits, and also likely affect the efficiency of in vitro embryo production.

Further advances in sequencing technologies include the development of long-read sequencing, yielding 20-kb sequence reads, which will improve existing livestock reference genome sequences which are still far from perfect. Once sequence data is available from a sufficient number of animals to define haplotypes in the population, it will be possible to predict high-density SNP genotypes from lowdensity data by "imputation", indeed prediction of wholegenome sequence from high-density data will be possible. This high-resolution genome data will make the identification of the variants responsible for phenotypic variation more rapid. Molecular breeding using high-density SNP and even genome sequence data promises to be a game changer, resulting in faster and more efficient genetic selection. In spite of the decreasing costs, whole-genome sequencing is still 5- to 10-time more expensive than SNP genotyping and, at low-sequence coverage, it gives lowconfidence genotype calls due to allelic drop-out in lowcoverage genomic regions. Whole-genome sequencing could be expected to replace other genotyping methods in the near future as costs fall further.

\section{Functional genomics Genome editing}

Methods to introduce genetic variation into the genomes of animals have been used for many years, with the first transgenic mouse produced in 1981 [36]. However, the early transgenic approaches were unpredictable, unrepeatable [37], and invariably resulted in the insertion of the exogenous DNA into the host genome at multiple sites and in multiple copies. In some cases, this led to disruption of gene function, undesired ectopic expression that was difficult to control, and over- or under-expression of the inserted gene. Very recently methods for sitespecific genetic modification have become available, and are now routinely used in research. These site-specific modifications are achieved by targeted cleavage of DNA and homologous recombination using zinc finger nucleases (ZFN), which are chimeric molecules, composed of a nuclease domain and specifically-designed DNA-recognition domains [38-40].

A more efficient molecular tool for genome editing is the clustered regularly interspaced short palindromic repeats (CRISPR)-associated 9 (Cas9) system. CRISPR/ Cas9 uses short, single-guide RNA (sgRNA) to recognize target sequences in the DNA for Cas9 nuclease cleavage to facilitate editing [41]. A further development is the transcription activator-like effector nucleases (TALEN) genome editing system. These are novel fusion proteins that originate from plant pathogens in the bacterial genus Xanthomonas and contain DNA-binding motifs, which, when coupled to the FokI nuclease, create efficient geneediting tools [42-44]. The TALEN and CRISPR/Cas9 systems are easier to engineer and more reliable than the use of zinc finger nucleases [45]. In the presence of single- or double-stranded DNA homologous to the target sequence, these systems can be used to introduce precise, targeted changes into the genome which may be deletions or additions of a few base pairs. It is also possible to introduce, delete or invert sequences of the genome that range in size from a few to several hundred nucleotides. It is even possible to target multiple genomic sites simultaneously and therefore modify several genes controlling complex traits, although the efficiency of multiple edits is still low. 
Genome editing has the potential to accelerate genetic improvement of farm animals, by moving existing variations among populations, which up to now has been achieved by introgression through cross-breeding and successive rounds of back-crossing. In contrast, to this lengthy introgression process, genome editing can move alleles into specific genetic backgrounds in one generation.

The effective application of genome editing requires improvements in in vitro embryo methods, to provide large numbers of oocytes and increased efficiency of in vitro embryo production. Oocytes can be obtained by OPU and in vitro fertilisation followed by microinjection of the zygotes and then in vitro culture until a transferable embryo stage is reached, typically the blastocyst stage [41]. Improvements will include the production of oocytes from young females for a range of farm animal species using JIVET, which has been used successfully to create large numbers of viable embryos, but currently only in sheep. Improvements in in vitro culture techniques are also required to ensure correct embryo development and maximise the number of live progeny produced.

\section{Biotech for breeding}

Genome editing has many applications for advanced breeding, from repairing defective genes, such as recessive lethal or heritable disease variations in high genetic merit sires, to the introduction of genes that have a major effect on commercially important traits, such as resistance to disease and stress or polledness. An example application is improving heat tolerance in European breeds for production in tropical environments. The SLICK mutation, which was discovered in the Senepol Caribbean cattle breed [46], improves heat tolerance since it is associated with short hair and increased sweating. The SLICK phenotype is under the control of a single gene [46]. There are several mutations in the prolactine receptor gene that cause the SLICK phenotype, one of which is a premature stop codon caused by a frameshift mutation [47]. Introgression of this mutation in different breeds with recurrent backcross designs is possible, but is slow, since it requires several generations of backcrosses to regain the genetic qualities of the recipient breed. Introduction of the SLICK variations into a breed could be achieved in a single generation by gene editing. The ability to get a rapid response by the introduction of alleles that help animals to adapt to new environments is important in the face of rapid climate changes that have been predicted.

\section{Interactions between functional genomics, reproductive biotechnologies and breeding}

Early developmental stages of in vitro produced embryos, up to blastocyst implantation, are associated with a high rate of failure. In sheep embryos, the period between day 20 and 30, during which there is the first functional interaction between the uterus and the extra-embryonic tissues leading to vascularisation, is a critical period. The success of this conceptus-mother interaction is affected by the epigenetic programming of the embryo, which in turn is affected by in vitro culture conditions. Comparison of the development of 89 naturally-conceived ovine conceptuses with 84 embryos produced in vitro revealed that a "foetal selection window", specifically between day 24 and 26 , is the period during which an epigeneticallycompromised conceptus is most likely to die [48]. To better understand this phenomenon, we have analysed the gross morphology, histology and gene expression profiles of the placenta from naturally-conceived and in vitro produced embryos. Our results showed that in vitro produced conceptuses have defective cardiovascular development and more frequent haemorrhages because of impaired blood vessel development and integrity. These defects are associated with a significant down-regulation of the expression of vascular and angiogenetic factors (FGF2, ANG2, TIE2 and HOXA13) detected in the placenta. Although these abnormalities in in vitro produced conceptuses were not necessarily lethal [49], there are clear deleterious implications for the lambs born from IVF procedures. Similar effects have been described, by others, for sheep IVF models [50], and similar placental anomalies have been observed for in vitro produced bovine embryos [51, 52].

It is likely that abnormalities associated with in vitro protocols have a common cause and may be due to epigenetic errors that accumulate during early development. These errors influence the establishment of the pregnancy, maternal-embryo communication and foetal development. Our work identified dysfunction of the DNA methylation machinery in the chorio-allantoic placenta from in vitro produced embryos [45]. During normal development, methylation of the gametic DNA is essentially lost shortly after fertilisation, and is then systematically re-established during early embryonic development, to be completely re-established by the blastocyst stage. In mammals, there are three major DNA methyltransferases, DNMT3a and b, which are involved in de novo methylation of DNA after embryo implantation, and DNMT1, which is necessary for the maintenance of established methylation patterns. A reduced DNMT1 activity may affect subsequent developmental processes. DNMT1 and cofactors (HDAC2, PCNA, DMAP1 and UHRF1) are significantly down-regulated in the placenta of in vitro produced embryos at very early developmental stages (day 20). As a consequence, expression of developmentally-important imprinted genes (IGF2, H19, PEG1/MEST and CDKN1C) are down-regulated. The 
methylation status of the maternal transcription factor H19 was also perturbed. These findings are in line with previous observations that epigenetic defects in the placenta result from in vitro embryo techniques, which are associated with growth arrest of the developing foetuses [53-55]. The expression profiles of imprinted genes varied among samples in our study and differ across studies $[56,57]$. This suggests that these epigenetic defects arise from stochastic processes.

Impairment of one-carbon metabolism (OCM) could be one of the factors affecting the methylation mechanisms that underlie the observed developmental defects. OCM includes a series of biochemical reactions that are involved in the transfer one-carbon groups, and thus have a critical role in establishing and maintaining DNA methylation patterns (methyl or $\mathrm{CH} 3$ groups) [58]. Early pre-implantation development is characterized first by active, then passive genome demethylation during subsequent cleavages, followed by an increase in global DNA methylation. This methylation is associated with the control of gene expression during early differentiation and the formation of the inner cell mass and trophoblast at the blastocyst stage [59]. Hence, an impaired OCM metabolic pathway, and a deficiency in associated cofactors during in vitro early embryonic development, will result in epigenetic defects and early embryonic developmental abnormalities. These abnormalities include pregnancy loss, neural tube defects, intrauterine growth retardation, abnormal foetal brain development, and impaired cardiovascular development in foetuses [60, 61]. In addition to these early effects, impaired OCM can also have longterm consequences into post-natal life, such as metabolic diseases and impaired cognitive and motor function [61, 62].

Cobalamin (also known as vitamin B12), which is one of the main cofactors involved in OCM, is not present in the commonly used culture media for in vitro embryo production. Cobalamin supplementation during in vitro maturation of sheep oocytes has been shown to positively affect their developmental competence and the subsequent DNA methylation profile at the blastocyst stage [63], presumably through the OCM pathway. Cobalamin supplementation of the culture medium during in vitro fertilisation of oocytes also resulted in improved placental vascularisation. The positive effect of cobalamin addition to culture medium appears to act at the molecular level by increasing expression of DNA methyltransferases, thus correcting epigenetic mis-programming and preventing vascular defects. Our data suggest that simple improvements to the culture media by the inclusion of factors, including cobalamin, are likely to increase the efficiency and reliability of in vitro embryo production and reduce developmental abnormalities [64].

\section{Conclusions}

There are potential benefits and synergies between genomic and reproductive technologies for sheep and cattle to enhance breeding programs. Advanced female reproductive technologies, such as MOET and JIVET [65] can increase the female contribution to the rate of genetic progress. Combining functional genetics and embryology to understand the epigenetic and gene expression effects of in vitro manipulation of gametes and embryos will contribute to optimising in vitro procedures; moreover, in vitro embryo biotechnologies, coupled with genome editing techniques, could provide the fittest phenotypes to withstand global climate changes [66]. Classically, modifications of protocols require validation through the production of offspring, which is time-consuming and expensive. However, molecular characterisation of in vitro produced embryos can provide information on the effects of changes in protocols, and indicate if these are beneficial or not. To conclude, improved in vitro embryo production is fundamental to enhance the genetic improvement of farm animals and the successful application of revolutionary techniques such as genome editing.

\section{Authors' contributions}

PL, PT, PAM, JW and FZ wrote the manuscript; GEP, FZ, AS, EC, PT provided unpublished data and suggestions; PL, JLW and PAM laid down the general structure and contents of the manuscript. All authors read and approved the final manuscript.

\section{Author details \\ ${ }^{1}$ Laboratory of Embryology, Faculty of Veterinary Medicine, University of Teramo, Teramo, Italy. ${ }^{2}$ Institute of Genetics and Animal Breeding of the Polish Academy of Sciences, Postepu 36A, Jastrzębiec, 05-552 Magdalenka, Poland. ${ }^{3}$ Istituto di Zootecnica, Università Cattolica del Sacro Cuore, Piacenza, Italy. ${ }^{4}$ Proteomic and Nutrigenomic Research Center - PRONUTRIGEN, Università Cattolica del Sacro Cuore, Piacenza, Italy. ${ }^{5}$ Institute of Agricultural Biology and Biotechnology, National Research Council, 26900 Lodi, Italy. ${ }^{6}$ Davies Research Centre, School of Animal and Veterinary Sciences, University of Adelaide, Roseworthy, SA 5371, Australia. ${ }^{7}$ Present Address: National Research Institute of Animal Production 1, Krakowska Street, 32-083 Balice n/ Kraków, Poland.}

\section{Acknowledgements}

The research leading to this publication was supported by the following Grants: Program FP7-KBBE-2012.1.3-04 GA 312097 (FECUND) to J.L.W. and G.P.; MIUR/CNR, Program FIRB GA B81J12002520001 (GenHome) to J.L.W. P.L., A.S. and P.A.M. P.L. and G.P. are participating in the COST action FA 1201 "Epiconcept" Epigenetic and Peri-conception Environment. This paper is part of the collection 'ISAFG2015' (6th International Symposium on Animal Functional Genomics, 27-29 July 2015, Piacenza, Italy). The publication of the papers in this collection was partly sponsored by OECD Co-operative Research Programme: Biological Resource Management for Sustainable Agricultural Systems (CRP). PL's participation in ISAFG2015 was financed by the OECD Co-operative Research Programme. The opinions expressed and arguments employed in this paper are the sole responsibility of the authors and do not necessarily reflect those of the OECD or of the governments of its Member countries.

\section{Competing interests \\ The authors declare that they have no competing interests.}

Received: 29 February 2016 Accepted: 15 July 2016

Published online: 01 August 2016 


\section{References}

1. Pieterse MC, Vos PL, Kruip TA, Willemse AH, Taverne MA. Characteristics of bovine estrous cycles during repeated transvaginal, ultrasound-guided puncturing of follicles for ovum pick-up. Theriogenology. 1991;35:401-13.

2. Kruip TA, Pieterse MC, van Beneden TH, Vos PL, Wurth YA, Taverne MA. A new method for bovine embryo production: a potential alternative to superovulation. Vet Rec. 1991;128:208-10.

3. Loi P, Ptak G, Dattena M, Ledda S, Naitana S, Cappai P. Embryo transfer and related technologies in sheep reproduction. Reprod Nutr Dev. 1998;38:615-28

4. Colleau JJ. Using embryo sexing within closed mixed multiple ovulation and embryo transfer schemes for selection on dairy cattle. J Dairy Sci. 1991;74:3973-84.

5. Dattena M, Ptak G, Loi P, Cappai P. Survival and viability of vitrified in vitro and in vivo produced ovine blastocysts. Theriogenology. 2000;53:1511-9.

6. Ptak G, Dattena M, Loi P, Tischner M, Cappai P. Ovum pick-up in sheep: efficiency of in vitro embryo production, vitrification and birth of offspring. Theriogenology. 1999:52:1105-14.

7. Ptak G, Loi P, Dattena M, Tischner M, Cappai P. Offspring from one-monthold lambs: studies on the developmental capability of prepubertal oocytes. Biol Reprod. 1999;61:1568-74.

8. Willadsen SM. A method for culture of micromanipulated sheep embryos and its use to produce monozygotic twins. Nature. 1979;277:298-300.

9. Heyman Y, Vignon X, Chesné P, Le Bourhis D, Marchal J, Renard JP. Cloning in cattle: from embryo splitting to somatic nuclear transfer. Reprod Nutr Dev. 1998;38:595-603.

10. Lopes RF, Forell F, Oliveira AT, Rodrigues JL. Splitting and biopsy for bovine embryo sexing under field conditions. Theriogenology. 2001;56:1383-92.

11. Willadsen SM. Nuclear transplantation in sheep embryos. Nature. 1986;320:63-5.

12. Willadsen SM. Cloning of sheep and cow embryos. Genome. 1989;31:956-62

13. Galli C, Duchi R, Colleoni S, Lagutina I, Lazzari G. Ovum pick up, intracytoplasmic sperm injection and somatic cell nuclear transfer in cattle, buffalo and horses: from the research laboratory to clinical practice. Theriogenology. 2014;81:138-51.

14. Loi P, Ledda S, Fulka J Jr, Cappai P, Moor RM. Development of parthenogenetic and cloned ovine embryos: effect of activation protocols. Biol Reprod. 1998;58:1177-87

15. Wilmut I, Schnieke AE, McWhir J, Kind AJ, Campbell KH. Viable offspring derived from fetal and adult mammalian cells. Nature. 1997;385:810-3.

16. Galli C, Lagutina I, Crotti G, Colleoni S, Turini P, Ponderato N, Duchi R, Lazzari G. Pregnancy: a cloned horse born to its dam twin. Nature. 2003:424:635.

17. Oback B, Wells DN. Cloning cattle. Cloning Stem Cells. 2004;5:243-56.

18. Meuwissen TH, Hayes BJ, Goddard ME. Prediction of total genetic value using genome-wide dense marker maps. Genetics. 2001;157:1819-29.

19. Young LE, Fernandes K, McEvoy TG, Butterwith SC, Gutierrez CG, Carolan $C$, et al. Epigenetic change in IGF2R is associated with fetal overgrowth after sheep embryo culture. Nat Genet. 2001;27:153-4.

20. Hill PW, Amouroux R, Hajkova P. DNA demethylation, Tet proteins and 5-hydroxymethylcytosine in epigenetic reprogramming: an emerging complex story. Genomics. 2014;104:324-33.

21. Urrego R, Rodriguez-Osorio N, Niemann H. Epigenetic disorders and altered gene expression after use of assisted reproductive technologies in domestic cattle. Epigenetics. 2014;9:803-15.

22. Akagi S, Matsukawa K, Takahashi S. Factors affecting the development of somatic cell nuclear transfer embryos in cattle. J Reprod Dev. 2014;60:329-35.

23. Firas J, Liu X, Polo JM. Epigenetic memory in somatic cell nuclear transfer and induced pluripotency: evidence and implications. Differentiation. 2014:88:29-32.

24. Bousquet D, Blondin P. Potential uses of cloning in breeding schemes: dairy cattle. Cloning Stem Cells. 2004;6:190-7.

25. Kelly JM, Kleemann DO, Walker SK. Enhanced efficiency in the production of offspring from 4- to 8-week-old lambs. Theriogenology. 2005;63:1876-90

26. Iheshiulor OO, Woolliams JA, Yu X, Wellmann R, Meuwissen TH. Withinand across-breed genomic prediction using whole-genome sequence and single nucleotide polymorphism panels. Genet Sel Evol. 2016;48:15.
27. Minozzi G, Nicolazzi EL, Stella A, Biffani S, Negrini R, Lazzari B, et al. Genome wide analysis of fertility and production traits in Italian Holstein cattle. PLoS One. 2013;8:e80219.

28. Höglund JK, Buitenhuis B, Guldbrandtsen B, Lund MS, Sahana G. Genome-wide association study for female fertility in Nordic Red cattle. BMC Genet. 2015;16:110.

29. Fritz S, Capitan A, Djari A, Rodriguez SC, Barbat A, Baur A, et al. Detection of haplotypes associated with prenatal death in dairy cattle and identification of deleterious mutations in GART, SHBG and SLC37A2. PLoS One. 2013;8:e65550

30. Kadri NK, Sahana G, Charlier C, Iso-Touru T, Guldbrandtsen B, Karim L, et al. A 660-Kb deletion with antagonistic effects on fertility and milk production segregates at high frequency in Nordic Red cattle: additional evidence for the common occurrence of balancing selection in livestock. PLoS Genet. 2014;10:e1004049.

31. McClure MC, Bickhart D, Null D, Vanraden P, Xu L, Wiggans G, et al. Bovine exome sequence analysis and targeted SNP genotyping of recessive fertility defects $\mathrm{BH} 1, \mathrm{HH} 2$, and $\mathrm{HH} 3$ reveal a putative causative mutation in SMC2 for HH3. PLoS One. 2014;9:e92769.

32. Sahana G, Nielsen US, Aamand GP, Lund MS, Guldbrandtsen B. Novel harmful recessive haplotypes identified for fertility traits in Nordic Holstein cattle. PLoS One. 2013:8:e82909.

33. VanRaden PM, Olson KM, Null DJ, Hutchison JL. Harmful recessive effects on fertility detected by absence of homozygous haplotypes. J Dairy Sci. 2011;94:6153-61.

34. Pausch $\mathrm{H}$, Schwarzenbacher $\mathrm{H}$, Burgstaller J, Flisikowski K, Wurmser C, Jansen $\mathrm{S}$, et al. Homozygous haplotype deficiency reveals deleterious mutations compromising reproductive and rearing success in cattle. BMC Genomics. 2015;16:312

35. Daetwyler HD, Capitan A, Pausch H, Stothard P, van Binsbergen R, Brøndum RF, et al. Whole-genome sequencing of 234 bulls facilitates mapping of monogenic and complex traits in cattle. Nat Genet. 2014;46:858-65.

36. Gordon JW, Ruddle FH. Integration and stable germ line transmission of genes injected into mouse pronuclei. Science. 1981;214:1244-6.

37. Capecchi MR. Gene targeting in mice: functional analysis of the mammalian genome for the twenty-first century. Nat Rev Genet. 2005:6:507-12.

38. Rouet P, Smih F, Jasin M. Expression of a site-specific endonuclease stimulates homologous recombination in mammalian cells. Proc Natl Acad Sci USA. 1994;91:6064-8

39. Smih F, Rouet P, Romanienko PJ, Jasin M. Double-strand breaks at the target locus stimulate gene targeting in embryonic stem cells. Nucleic Acids Res. 1995:23:5012-9.

40. Petersen $\mathrm{B}$, Niemann $\mathrm{H}$. Advances in genetic modification of farm animals using zinc-finger nucleases (ZFN). Chromosome Res. 2015:23:7-15.

41. Wang X, Yu H, Lei A, Zhou J, Zeng W, Zhu H, et al. Generation of genemodified goats targeting MSTN and FGF5 via zygote injection of CRISPR/ Cas9 system. Sci Rep. 2015;5:13878.

42. Boch J, Scholze H, Schornack S, Landgraf A, Hahn S, Kay S, et al. Breaking the code of DNA binding specificity of TAL-type III effectors. Science. 2009;326:1509-12.

43. Christian M, CermakT, Doyle EL, Schmidt C, Zhang F, Hummel A, et al. Targeting DNA double-strand breaks with TAL effector nucleases. Genetics. 2010;186:757-61.

44. Mahfouz MM, Li L, Piatek M, Fang X, Mansour H, Bangarusamy DK, et al. Targeted transcriptional repression using a chimeric TALE-SRDX repressor protein. Plant Mol Biol. 2012;78:311-21.

45. Gaj T, Gersbach CA, Barbas CF 3rd. ZFN, TALEN, and CRISPR/Cas-based methods for genome engineering. Trends Biotechnol. 2013;31:397-405.

46. Olson TA, Lucena C, Chase CC Jr, Hammond AC. Evidence of a major gene influencing hair length and heat tolerance in Bos taurus cattle. J Anim Sci. 2003;81:80-90.

47. Littlejohn MD, Henty KM, Tiplady K, Johnson T, Harland C, et al. Functionally reciprocal mutations of the prolactin signalling pathway define hairy and slick cattle. Nat Commun. 2014:5:5861.

48. Ptak GE, D'Agostino A, Toschi P, Fidanza A, Zacchini F, Czernik M, et al. Post-implantation mortality of in vitro produced embryos is associated with DNA methyltransferase 1 dysfunction in sheep placenta. Hum Reprod. 2013:28:298-305. 
49. Fidanza A, Toschi P, Zacchini F, Czernik M, Palmieri C, Scapolo P, et al. Impaired placental vasculogenesis compromises the growth of sheep embryos developed in vitro. Biol Reprod. 2014;91:21.

50. Grazul-Bilska AT, Johnson ML, Borowicz PP, Bilski JJ, CymbalukT, Norberg $S$, et al. Placental development during early pregnancy in sheep: effects of embryo origin on vascularization. Reproduction. 2014;147:639-48.

51. Salilew-Wondim D, Tesfaye D, Hossain M, Held E, Rings F, Tholen E, et al. Aberrant placenta gene expression pattern in bovine pregnancies established after transfer of cloned or in vitro produced embryos. Physiol Genomics. 2013;45:28-46.

52. Farin PW, Piedrahita JA, Farin CE. Errors in development of fetuses and placentas from in vitro-produced bovine embryos. Theriogenology. 2006;65:178-91.

53. de Waal E, Vrooman LA, Fischer E, Ord T, Mainigi MA, Coutifaris C, et al. The cumulative effect of assisted reproduction procedures on placental development and epigenetic perturbations in a mouse model. Hum Mol Genet. 2015;24:6975-85.

54. Wrenzycki $\mathrm{C}$, Niemann $\mathrm{H}$. Epigenetic reprogramming in early embryonic development: effects of in vitro production and somatic nuclear transfer. Reprod Biomed Online. 2003;7:649-56.

55. de Waal E, Mak W, Calhoun S, Stein P, Ord T, Krapp C, et al. In vitro culture increases the frequency of stochastic epigenetic errors at imprinted genes in placental tissues from mouse concepti produced through assisted reproductive technologies. Biol Reprod. 2014;90:22.

56. Rivera RM, Stein P, Weaver JR, Mager J, Schultz RM, Bartolomei MS Manipulations of mouse embryos prior to implantation result in aberrant expression of imprinted genes on day 9.5 of development. Hum Mol Genet. 2008;17:1-14.

57. Nelissen EC, Dumoulin JC, Daunay A, Evers JL, Tost J, van Montfoort AP. Placentas from pregnancies conceived by IVF/ICSI have a reduced DNA methylation level at the $\mathrm{H} 19$ and MEST differentially methylated regions. Hum Reprod. 2013;28:1117-26.
58. Friso S, Choi SW. Gene-nutrient interactions and DNA methylation. J Nutr. 2002;132(8 Suppl):2382S-7S.

59. Morgan HD, Santos F, Green K, Dean W, Reik W. Epigenetic reprogramming in mammals. Hum Mol Genet. 2005;14:R47-58.

60. Ikeda S, Koyama H, Sugimoto M, Kume S. Roles of one-carbon metabolism in preimplantation period-effects on short-term development and long-term programming. J Reprod Dev. 2012;58:38-43.

61. Rush EC, Katre P, Yajnik CS. Vitamin B12: one carbon metabolism, fetal growth and programming for chronic disease. Eur J Clin Nutr. 2014;68:2-7.

62. Pepper MR, Black MM. B12 in fetal development. Semin Cell Dev Biol. 2011;22:619-23.

63. Zacchini F, Toschi P, Loi P, Ptak G. Cobalamin supplementation during in vitro maturation improves preimplantation development of sheep embryos. Reprod Fertil Dev. 2014;27:244.

64. Iuso D, Czernik M, Toschi P, Fidanza A, Zacchini F, Feil R, et al. Exogenous expression of human protamine 1 (hPrm 1 ) remodels fibroblast nuclei into spermatid-like structures. Cell Rep. 2015;13:1765-71.

65. Granleese T, Clark SA, Swan AA, van der Werf JH. Increased genetic gains in sheep, beef and dairy breeding programs from using female reproductive technologies combined with optimal contribution selection and genomic breeding values. Genet Sel Evol. 2015:47:70.

66. Dikmen S, Khan FA, Huson HJ, Sonstegard TS, Moss JI, Dahl GE, et al. The SLICK hair locus derived from Senepol cattle confers thermotolerance to intensively managed lactating Holstein cows. J Dairy Sci. 2014;97:5508-20.

\section{Submit your next manuscript to BioMed Central and we will help you at every step:}

- We accept pre-submission inquiries

- Our selector tool helps you to find the most relevant journal

- We provide round the clock customer support

- Convenient online submission

- Thorough peer review

- Inclusion in PubMed and all major indexing services

- Maximum visibility for your research

Submit your manuscript at www.biomedcentral.com/submit

(OioMed Central 